\title{
Effect of organo-montmorillonite nanoclay on VOCs inhibition of bitumen
}

Liping $\mathrm{Li}^{1}$, Shaopeng $\mathrm{Wu}^{2}$, Gang $\mathrm{Liu}^{3}{ }^{3}$, Tingwei $\mathrm{Cao}^{4}$, Serji Amirkhanian ${ }^{5}$

${ }^{1}$ State Key Laboratory of Silicate Materials for Architectures, Wuhan University of Technology, Wuhan, 430070, China, lipingli@whut.edu.cn

${ }^{2}$ State Key Laboratory of Silicate Materials for Architectures, Wuhan University of Technology, Wuhan, 430070, China, wusp@whut.edu.cn

${ }^{3}$ State Key Laboratory of Silicate Materials for Architectures, Wuhan University of Technology, Wuhan, 430070, China, $\underline{\text { liug@whut.edu.cn }}$

${ }^{4}$ Hubei Provincial Academy of Building Research and Design, Wuhan, 430070, China, ctw-123@163.com

${ }^{5}$ State Key Laboratory of Silicate Materials for Architectures, Wuhan University of Technology, Wuhan, 430070, China, and University of Alabama, samirkhanian@ueng.ua.edu *Corresponding author, E-mail: liug@ whut.edu.cn 


\section{Abstract:}

The volatile organic compounds (VOCs) emission from bituminous materials can lead to serious environmental and health issues during their applications. In this study, organo-montmorillonite nanoclays were used to modify the base bitumen, and their effect on inhibiting the VOCs emission of bitumen was evaluated by pyrolysis gas chromatograph interfaced with mass spectrometer (Py-GC/MS). Laboratory ageing study was designed and tested to evaluate the effects of the nanoclay on the ageing resistance of base binder. The results indicated that the nanoclay can effectively inhibit the VOCs emission of bitumen. The reason can be that the light components of bitumen were intercalated into the interlayer space of nanoclay which limited their emission. The organic surfactant on the surface of the nanoclay played an important role to determine the compatibility between the nanoclay and the bitumen, and it finally determined this inhibition effect. The ageing resistance of modified bitumen improved not only due to the block effect of nanoclay to the oxygen invasion, but also due to its inhibition to VOCs emission at high production temperatures. Therefore, the organo-montmorillonite can function as an inhibitor of VOCs emission and at the same time improve the ageing resistance.

Key words: Bitumen; Montmorillonite; Surfactant; VOCs; Py-GC/MS 


\section{Introduction}

The emissions of volatile organic compounds (VOCs) in bitumens can lead to serious health and environmental problems. Components of VOCs during the application of bitumen are very complicated, normally containing alkanes, sulfur hydrocarbons, polycyclic aromatic hydrocarbons etc. Emissions can occur during the production transport and paving of asphalt mixtures and other application[1]. Bitumen binder has been used in road construction, roofing, coating, and many other applications for many decades. It behaves as a visco-elastic material at the ambient temperature but has to be heated prior to be used in order to lower the viscosity ensuring its application at a high temperature (normally higher than $150^{\circ} \mathrm{C}$ ). For some special applications, like guss-asphalt used on the steel bridge deck, the paving temperature is as high as $230{ }^{\circ} \mathrm{C}$. Warm mixture and cold mixtures (emulsion, foamed bitumen mixtures) more and more attract the attention of the road engineers. The temperature is the key factor to cause the emission of VOCs in the bitumen fume [2, 3]. Bitumen is the residue of the refining of crude oil. Through the vacuum distillation and different blowing process, the bitumen with different penetration grades can be manufactured. The properties of bitumen is a function of both the origin of the crude oil and the manufacturing process [4]. Therefore, three factors, application temperature, the crude oil source and the manufacturing process determine the characteristics of VOCs in the bitumen fume.

The VOCs belong to a special category of atmospheric pollutants and can affect human health in both acute and chronic ways through inhalation and skin 
contamination [5]. It can pose a potential health risk to the workers who are working on production, transporting or constructing bituminous materials. It has been reported that European road paving workers can be exposed to $0.1-2 \mathrm{mg} / \mathrm{m}^{3}$ bitumen fume including $10-200 \mathrm{ng} / \mathrm{m}^{3}$ benzo a pyrene [6-8]. In the United States, more than half a million workers were exposed to asphalt fumes in the field operations. The research also indicated that the roofers had a higher risk for the same cancers than road pavers and highway maintenance workers [9]. The roofers had a higher risk for the same cancers than road pavers and highway maintenance workers because they melt the binder with burners and that is more dangerous and not well controlled. Besides, the VOCs deplete the ozone layer and formed secondary aerosols [10]. Furthermore, the VOCs emission can change the properties of bituminous materials and make them harder [11]. Therefore, the reduction of the emission of VOCs from bituminous materials has to be investigated in more detail and be the objective of protocols and policies by the environmental departments and road sectors all over the world.

Many researchers have been performing studies to characterize the properties of VOCs from bituminous materials and its release mechanism related to the molecular movement at elevated temperature [12-15]. However, less effective methods have been found to reduce the VOCs emission. For instance, the warm mix agents have been used in the asphalt mixture to reduce its application temperature during the construction of the pavement [16-18]. But these agents may not be suitable in all bitumen applications like in roofing [4]. Some additives, like active carbon and layered double hydroxides have been introduced into bitumen to inhibit the emission 
of VOCs characterized due to the porosity [19-21].

As a layered-silicate nanoclay, organo-montmorillonite proved to be effective in improving the ageing resistance of bitumen due to its intercalated structure in the bitumen and the barrier properties to the invasion of oxygen [22, 23]. However, its inhibition effect to VOCs emission of bitumen has not been established yet. This study evaluated the effect of organo-montmorillonites with different surfactants on the inhibition to the VOCs emission. VOCs are analysed by Pyrolysis Gas Chromatography interfaced with Mass Spectrometers (GC/MS), allowing the identification and quantification of these complex carbon compounds. The results were expected to provide a potential solution to decrease this emission.

\section{Experimental}

\subsection{Materials}

Base bitumen (SK-90) with a penetration grade of 90 was imported from South Korea and used in this study. Its basic properties are given in Table 1. Two types of organo-montmorillonite (Mt) clay, Mt1 and Mt2, were used in this study. Mt1 and Mt2 were obtained through organically treating inorganic $\mathrm{Na}^{+}$-based montmorillonite with octadecyl trimethyl ammonium salt and benzyl dimethyl hexadecyl ammonium salt, respectively. After the replacement reaction, the surfactant cations whose molecular structures are shown in Figure 1 replaced $\mathrm{Na}^{+}$cations, and the inorganic $\mathrm{Mt}$ became hydrophobic. Physical properties of these two Mts are given in Table 2, and more information about the properties of Mts used in this study can be found in another publication [24]. 


\subsection{Preparation of Mt modified bitumen}

To prepare the modified bitumen samples, $500 \mathrm{~g}$ of base bitumen was heated and poured into a $1000 \mathrm{ml}$ cylindrical container placed on a heating plate. Approximately $5 \%$ of Mt by weight of base bitumen was added gradually to the bitumen and dispersed with a low-speed mixer at $100 \mathrm{rpm}$ for $10 \mathrm{~min}$, at a temperature of $145^{\circ} \mathrm{C}$. Then, a high-shearing mixer (ESR-500) was used at $4500 \pm 500 \mathrm{rpm}$ for $1 \mathrm{~h}$ at the same temperature. The base bitumen was also subjected to the same processing for comparison purposes. All samples were cooled down to room temperature and stored for further testing.

\subsection{Testing}

\subsubsection{Pyrolysis gas chromatograph interfaced with mass spectrometer}

Pyrolysis gas chromatograph interfaced with mass spectrometer (Py-GC/MS) was adopted in evaluating the VOCs emission of base and modified bitumens. In this system, pyrolyzer apparatus CDS 5150 produced by CDS Company America and gas chromatograph interfaced with mass spectrometer with the model of 7890/5975 Agilent company America were used. At first, $6.6 \pm 0.02 \mathrm{mg}$ of sample was loaded into a quartz tube with quartz wool placed at the both ends. Then, this tube was placed at the chamber of the pyrolyzer with helium as a carrier gas at a constant flow of 1.0 $\mathrm{mL} / \mathrm{min}$. The temperature in the chamber of pyrolyzer was initially set at $50{ }^{\circ} \mathrm{C}$ and rapidly increased to $230{ }^{\circ} \mathrm{C}$ at a rate of $10^{\circ} \mathrm{C} / \mathrm{ms}$, holding for $1 \mathrm{~min}$. Because $230{ }^{\circ} \mathrm{C}$ was very close to the highest temperature of bitumen during its application, this temperature was chosen for the pyrolysis. Next, the VOCs of samples were injected 
into the GC for separation by using a capillary column (Agilent 222-5532LTM) with a length of $30 \mathrm{~m}$ and a cross section of $0.25 \mathrm{~mm} \times 0.25 \mu \mathrm{m}$. The GC oven was programmed at $15{ }^{\circ} \mathrm{C} / \mathrm{min}$ from $50{ }^{\circ} \mathrm{C}$ to $100{ }^{\circ} \mathrm{C}$, and then at $6{ }^{\circ} \mathrm{C} / \mathrm{min}$ to $250{ }^{\circ} \mathrm{C}$ for 2min holding to extrude the VOCs. Mass spectrometer (MS) was carried out with a positive electron ionization $(\mathrm{EI})$ resource $(70 \mathrm{eV})$ at $230{ }^{\circ} \mathrm{C}$ and a full scan mode with mass-to-charge ratio $(\mathrm{m} / \mathrm{z})$ ranging from 30 to $800 \mathrm{amu}$.

\subsubsection{Laboratory ageing}

Bitumen ageing happens during two periods: short term ageing during its production temperatures caused by emission of VOCs and oxidation and long term ageing probably in time due to oxidation. Ageing can make bitumen become hard and brittle, and it includes the VOCs emission and the oxidation of the bitumen. Approximately $50 \pm 0.5 \mathrm{~g}$ of bitumen sample was poured in a pan with a diameter of $140 \mathrm{~mm}$ at $145^{\circ} \mathrm{C}$. Thickness of the film was measured to be about $3.2 \mathrm{~mm}$. Then, the pan was placed in a vacuum oven at $180{ }^{\circ} \mathrm{C}$ for 8 hours to evaluate how the VOCs emissions influence the properties of bitumen. Under the condition of vacuum, the oxidation can hardly happen, and only volatiles are lost in this case. The pan with the same bitumen sample was placed in draft oven at $180{ }^{\circ} \mathrm{C}$ for 8 hours to create the oxidation.

\subsubsection{Rheological properties}

Dynamic shear rheometer (DSR) AR 2000ex Anton Paar was used to measure the dynamic rheological properties of blended binders, following EN 14770 [25]. The test is used to characterize both viscous and elastic behavior of bitumen binder by measuring the complex shear modulus, $\mathrm{G}^{*}$. Then, the complex viscosity $\eta^{*}$, equal to 
$\mathrm{G}^{*} / \omega$ of the binder is determined, where $\omega$ is the frequency, $\mathrm{rad} / \mathrm{s}$. The temperature range is between $-10^{\circ} \mathrm{C}$ and $60^{\circ} \mathrm{C}$. The power-law relationship between $\eta^{*}$ and $\omega$ was built up, as shown below [26]:

$$
\left|\eta^{*}\right|=m \cdot \omega^{n-1}
$$

where $\mathrm{m}$ is the parameter and $\mathrm{n}$ is the flow index. When $\mathrm{n}$ equals to 1 , it means that the binder is a Newtonian liquid which its viscosity becomes independent on the shear rate or oscillation frequency (for the case in this study); when $n<1$, the binder has the pseudoplastic properties. Garcia [27] defined a near-Newtonian behaviour for the bituminous binder when $\mathrm{n}$ was between 0.9 and 1 . This range represented the transition from pseudoplastic to Newtonian behavior of bitumen.

\section{Results and Discussions}

\subsection{Chemical characteristics of organo-montmorillonite}

Figure 2 shows that the pyrolysis can lead to the release of volatile chemical compounds in Mt1 and Mt2. Corresponding compounds are given in Tables 3 and 4. As indicated, pyrolyzed products from Mt1 were dominated by n-alkane hydrocarbons. The alkanes ranged from $\mathrm{C}_{14}$ to $\mathrm{C}_{18}$, with a maximum peak area at $\mathrm{C}_{17}$ (Figure 2a and Table 3). It was known that the surface of Mt1 was organically treated by the surfactant of octadecyl trimethyl ammonium. Therefore, these volatile compounds can be the thermal decompositions of the surfactant in Mt1. The compound, labeled by Mt1-6 in Table 3, containing nitrogen should be from the quaternary ammonium salt and formed during thermal cracking of the surfactant. The product of Mt1-7 was difficult to be identified with a lower match quality of 59 . 
The pyrolysized products of Mt2 were dominated by aliphatic hydrocarbons (n-alkane and n-alkene), with a maximum peak area of Mt2-5 (1-Decene) (Figure 2b and Table 4). In comparison, the volatile chemical compounds from Mt2 were more complex than that from Mt1, due to a complicated molecular structure of the surfactant (Figure 1b) in the interlayer space of Mt2. It was found that there was a huge peak area of Mt2-2 which was identified as benzyl chloride. The reason can be that there were still some free surfactant chloride salts remaining in Mt2 after the modification.

\subsection{VOCs emission of bitumen before and after modification}

Figure 3 shows the Py-GC/MS chromatograms of base and modified asphalt binders. In total, there were 18 VOCs peaks formed due to the effects of thermal cracking on base binder (Figure 3a). As indicated in Table 5, the main compounds of base binder were aliphatic hydrocarbons (n-alkane and n-alkene), extending to $\mathrm{C}_{21}$ at the peak of Base-16, and meanwhile with a maximum peak area of Base-5. These compounds could be very close to those in the fume of bitumen released during its application. As one of four broad component groups, saturates consist of straight and branch chain aliphatic hydrocarbons. Therefore, the VOCs released from the base bitumen can be mainly the pyrolysized products of saturates in the bitumen. It also concluded that how to minimize the emission of the volatile chemical compounds from saturates was a key factor in reducing the VOCs emission of bitumen fume during its application.

After the modification with Mt1, it was found that 6 VOCs peaks of base bitumen disappeared, i.e. Base-4, $-8,-12,-14,-16$ and -18 (Figure $3 b$ and Table 5). Most of them were aliphatic hydrocarbons. Meanwhile, the peak areas for other compounds 
were decreased, especially for Base-5, i.e. tetradecane (Figure 4a). It was indicated that organo-montmorillonite can inhibit the VOCs emission of base bitumen. Previous studies indicated that an intercalated structure of organo-montmorillonite can form in the base bitumen, i.e. that some bituminous molecules were present in the interlayer space of montmorillonite with a thickness around 2 4 $\mathrm{nm}$ [22]. It can be concluded that saturates mainly consisting of aliphatic hydrocarbons were the main component of bitumen to be intercalated in the interlayer space of Mt. In this way, their emission was reduced due to the limitation by the Mt layers during the process of thermal cracking. It was hard for asphaltenes to be present in this space since they had a large molecular scale up to 5-30 $\mathrm{nm}[4]$.

For Mt1 modified bitumen (Figure 3b), it was noted that the peaks of Mt1-1, -2, -3 and -4 from Mt1 nanoclay overlapped with Base-5, -7, -9 and -11 from base bitumen, respectively. Due to a very low concentration of Mt (5\% by weight) in the bitumen, these compounds should result from the pyrolysis of base bitumen. Mt1-5 can still be detected within a small area, but Mt1-6 and -7 have disappeared. One new compound marked with "*” was detected in the volatile chemical compounds of Mt1 modified bitumen, but it was hard to be identified due to a complicated molecular structure. It might be some composite synthesized during the thermal cracking of the modified bitumen or pyrolyzed from resin or asphaltenes.

As shown in Figure 3c, there were four VOCs peaks (Base-4, -8, -16 and -17) of base bitumen disappearing after being modified with Mt2. For the samples tested in this study, except Base-17, others were aliphatic hydrocarbons. As shown in Figure 4b, the 
emission of left 12 VOCs in the fume of base bitumen were detected, and it indicated that they were inhibited by the nanoclay, especially for Base-5, i.e. tetradecane. It was concluded that Mt2, the same as Mt1, can also limit the emission of VOCs from the base bitumen. Meanwhile, there were three new compounds in the fume whose chemical formulas were too complex to be identified (see Figure 3c). With respect to Mt2 itself, four peaks (Mt2-2, -6, -8 and -13) can still be detected (see Figure 3c). It was noted that the peak of Mt2-6 and -8 overlapped with those of Bases-7 and -11 , respectively. There was a big peak for benzyl chloride (Mt2-2). This compound was believed to be the pyrolysized product of free surfactant salt in Mt2, which is explained in the section of 3.1 .

In comparison, Mt1 can minimize the emission of VOCs more than Mt2. The total area of VOCs for base bitumen (calculated from Table 5), Mt1 and Mt2 modified bitumens were $993527.8,450890.6$ and 546855.1, respectively. It was indicated that Mt1 can reduce half content of VOCs emission from the base bitumen. It was known that the surfactants on the surface of Mt1 layers with an aliphatic hydrocarbon structure were more compatible to saturate component in the bitumen than the surfactants of MT2. Four overlapping VOCs peaks between Mt1 and base bitumen can further prove it. Therefore, saturates in the base bitumen were easier to be intercalated in the interlayer space of Mt1 than in that of Mt2; hence, it was concluded that Mt1 had a better inhabitation effect than Mt2.

\subsection{Ageing properties}

As shown in Figure 5a, the flow curve of base bitumen after vacuum ageing was 
located below that of the fresh base. It meant that vaccuum condition reduced the flow behaviour due to the emission of light components. However, draft oven ageing can can make the binder harder. Such as, the flow index at $-10{ }^{\circ} \mathrm{C}$ decreased nearly by double from 0.43 to 0.22 . The reason can be that both the emission of light component and the oxidaiton of the bitumen hardened the base bitumen.

As shown in Figures $5 \mathrm{~b}$ and $5 \mathrm{c}$, the flow curves of modified bitumen before and after the vacuum ageing are very comparable. According to the Py-GC/MS results in the section of 3.2, the reason can be that nanoclay inhibited the emission of light component of the bitumen and made it less stiff. In comparison, nanoclay Mt1 were more effective to reduce the change in the flow behaviour of bitumen than that of $\mathrm{Mt} 2$. It was consistant with the results characterized by the Py-GC/MS. These two graphs also show that draft oven ageing can further reduce the flow behavior due to the oxidation. However, the change in this behavior was less when compared with that of base bitumen. For example, the flow index of Mt1 modified bitumen at $-10{ }^{\circ} \mathrm{C}$ only changed from 0.26 to 0.24 after draft oven ageing. Besides the inhibition to the VOCs emission, the block effect to the oxygen invasion by nanoclay layers can be another important reason to reduce the change of flow behavior after draft oven ageing. Therefore, for the cases tested in this research study, nanoclay can be used as an ageing resistant.

\section{Conclusions}

The Py-GC/MS was an effective method to characterize the VOCs emission of bitumen. The organo-montmorillonite nanoclay can be used to inhibit the VOCs 
emission of bitumen. In comparison, nanoclay with the octadecyl trimethyl ammonium surfactants had a better inhibition effect to the VOCs emission than that with benzyl dimethyl hexadecyl ammonium surfactants. The reason can be that the former had a better compatibility with the light components of bitumen which were intercalated into the interlayer space of nanoclay. The ageing resistance of modified bitumen was improved not only due to the block effect of nanoclay to the oxygen invasion, but also due to its inhibition to VOCs emission. Therefore, organo-montmorillonite can function as an inhibitor of VOCs emission and an ageing resistant to be used in the modification of the bitumen.

\section{Acknowledgements}

This work was supported by the National Science Foundation for Young Scholars of China (grant numbers. 51608411); the Fundamental Research Funds for the Central Universities (WUT: 173101004 and WUT: 173201002); the International Science \& Technology Cooperation Program of China (grant numbers. 2013DFE83100); and the National Key Scientific Apparatus Development Program from the Ministry of Science and Technology of China (No. 2013YQ160501). We appreciate Dr. De Fang from Center for Materials Research and Analysis (Wuhan University of Technology) for GC/MS tests. 


\section{References}

[1] G. Boczkaj, A. Przyjazny, M. Kamiński, Characteristics of volatile organic compounds emission profiles from hot road bitumens, Chemosphere 107 (2014) 23-30.

[2] J.F. Wal, A.W. Hoogeveen, P. Wouda, The influence of temperature on the emission of volatile organic compounds from PVC flooring, carpet, and paint, Indoor air 7(3) (1997) 215-221.

[3] E. Gasthauer, M. Mazé, J. Marchand, J. Amouroux, Characterization of asphalt fume composition by GC/MS and effect of temperature, Fuel 87(7) (2008) 1428-1434.

[4] J. Read, D. Whiteoak, The shell bitumen handbook, Thomas Telford2003.

[5] U.B. Celebi, N. Vardar, Investigation of VOC emissions from indoor and outdoor painting processes in shipyards, Atmospheric Environment 42(22) (2008) 5685-5695.

[6] J. Wang, D.M. Lewis, V. Castranova, D.G. Frazer, T. Goldsmith, S. Tomblyn, J. Simpson, S. Stone,

A. Afshari, P.D. Siegel, Characterization of asphalt fume composition under simulated road paving conditions by GC/MS and microflow LC/quadrupole time-of-flight MS, Analytical Chemistry 73(15) (2001) 3691-700.

[7] I. Burstyn, H. Kromhout, T. Kauppinen, P. Heikkilä, P. Boffetta, Statistical modelling of the determinants of historical exposure to bitumen and polycyclic aromatic hydrocarbons among paving workers, Annals of Occupational Hygiene 44(1) (2000) 43-56.

[8] J.M. Antonini, J.R. Roberts, M.D. Taylor, X. Yin, S. Stone, A. Moseley, J.K.-H. Ma, D.G. Frazer, V. Castranova, J.Y. Ma, Effect of asphalt fume inhalation exposure at simulated road paving conditions prior to bacterial infection on lung defense responses in rats, Inhalation toxicology 15(13) (2003) $1347-1368$.

[9] C. Deutsch, P. Nicolosi, E. Jannitti, G. Tondello, M. Morando, M. Pusterla, R.A. Ricci, Volatile 
Organic Compounds Generated in Asphalt Pavement Construction and Their Health Effects on Workers, Journal of Construction Engineering \& Management 140(2) (2014) 40-43.

[10] M.O. Andreae, P.J. Crutzen, Atmospheric aerosols: Biogeochemical sources and role in atmospheric chemistry, Science 276(5315) (1997) 1052-1058.

[11] P. Cui, S. Wu, Y. Xiao, H. Zhang, Study on the deteriorations of bituminous binder resulted from volatile organic compounds emissions, Construction and Building Materials 68 (2014) 644-649.

[12] E. Gasthauer, M. Mazé, J.P. Marchand, J. Amouroux, Characterization of asphalt fume composition by GC/MS and effect of temperature, Fuel 87(7) (2008) 1428-1434.

[13] F. Deygout, Volatile emissions from hot bitumen storage tanks, Environmental Progress \& Sustainable Energy 30(1) (2011) 102-112.

[14] M.D.C. Rubio, F. Moreno, G. Martínez, J.M. Vázquez, Comparative analysis of emissions from the manufacture and use of hot and half-warm mix asphalt, Journal of Cleaner Production 41(1) (2013) $1-6$.

[15] P. Mahbub, A. Goonetilleke, G.A. Ayoko, P. Egodawatta, Effects of climate change on the wash-off of volatile organic compounds from urban roads, Science of the Total Environment 409(19) (2011) 3934-42.

[16] G.C. Hurley, B.D. Prowell, Evaluation of potential processes for use in warm mix asphalt, Journal of the Association of Asphalt Paving Technologists 75(4) (2006).

[17] S. Capitão, L. Picado-Santos, F. Martinho, Pavement engineering materials: Review on the use of warm-mix asphalt, Construction and Building Materials 36 (2012) 1016-1024.

[18] M.C. Rubio, G. Martínez, L. Baena, F. Moreno, Warm mix asphalt: an overview, Journal of Cleaner Production 24 (2012) 76-84. 
[19] P. Cui, S. Wu, F. Li, Y. Xiao, H. Zhang, Investigation on Using SBS and Active Carbon Filler to Reduce the VOC Emission from Bituminous Materials, Materials 7(9) (2014) 6130-6143.

[20] P.Q. Cui, S.P. Wu, Y. Xiao, H.H. Zhang, Experimental study on the reduction of fumes emissions in asphalt by different additives, Material Research Innovations 19(S1) (2015) S1-158-S1-161.

[21] P. Cui, S. Wu, Y. Xiao, M. Wan, P. Cui, Inhibiting effect of Layered Double Hydroxides on the emissions of volatile organic compounds from bituminous materials, Journal of Cleaner Production 3(12) (2015) 1151-6.

[22] G. Liu, S. Wu, M. Van de Ven, J. Yu, A. Molenaar, Influence of sodium and organo-montmorillonites on the properties of bitumen, Applied Clay Science 49(1) (2010) 69-73.

[23] G. Liu, S. Wu, M. van de Ven, J. Yu, A. Molenaar, Structure and artificial ageing behavior of organo montmorillonite bitumen nanocomposites, Applied Clay Science 72 (2013) 49-54.

[24] G. Liu, Characterization and identification of bituminous materials modified with montmorillonite nanoclay, TU Delft, Delft University of Technology2011.

[25] E.N.E. 14770, Methods of test for petroleum and its products. Bitumen and bituminous binders. Determination of complex shear modulus and phase angle. Dynamic Shear Rheometer (DSR). (2005).

[26] P.J. Carreau, D. De Kee, R.P. Chhabra, Rheology of polymeric systems: principles and applications, Hanser Publishers Munich1997.

[27] A. García, M. Bueno, J. Norambuena-Contreras, M.N. Partl, Induction healing of dense asphalt concrete, Construction and Building Materials 49 (2013) 1-7. 


\section{List of Tables and Figures}

Table 1 Basic properties of base bitumen

Table 2 Physical properties of two organo-montmorillonites Mt1 and Mt2

Table 3 The pyrolysized products of organo-montmorillonite Mt1

Table 4 Pyrolysized products of organo-montmorillonite Mt2

Table 5 Peak labels in the Py-GC/MS chromatogram of VOCs from base bitumen,

Mt1modified and Mt2 modified bitumens, their corresponding compounds and peak areas

Figure 1 Schematic molecular structures of quaternary ammonium salt cations: (a) in Mt1 and (b) in Mt2

Figure 2 Py-GC/MS chromatogram of organo-montmorillonites for (a) Mt1 and (b)

Mt2

Figure 3 The Py-GC/MS chromatograms of (a ) base bitumen (b) Mt1 modified bitumen (c) Mt2 modified bitumen (“*” in the figure means new compounds synthesized due to the thermal cracking of modified bitumen )

Figure 4 Change in the peak area of VOCs in the base bitumen after modification with (a) Mt1 and (b) Mt2

Figure 5 Flowability before and after different oven ageing for (a) base bitume, (b) Mt1 modified bitumen and (c) Mt2 modified bitumen 
Table 1 Basic properties of base bitumen

\begin{tabular}{lcl}
\hline Items & Values & Standards \\
\hline Penetration at $25^{\circ} \mathrm{C}[0.1 \mathrm{~mm}]$ & 92 & ASTM D5 \\
Softening point $\left[{ }^{\circ} \mathrm{C}\right]$ & 48 & ASTM D36 \\
Ductility at $15^{\circ} \mathrm{C}[\mathrm{cm}]$ & 153 & ASTM D113 \\
Viscosity at $60^{\circ} \mathrm{C}[\mathrm{Pa} \cdot \mathrm{s}]$ & 168 & ASTM D4402 \\
Viscosity at $135^{\circ} \mathrm{C}[\mathrm{Pa} \cdot \mathrm{s}]$ & 0.53 & ASTM D4402 \\
\hline
\end{tabular}


Table 2 Physical properties of two organo-montmorillonites Mt1 and Mt2

\begin{tabular}{lcc}
\hline Items & Mt1 & Mt2 \\
\hline Basal spacing $[\mathrm{nm}]$ & 2.1 & 2.6 \\
Density $\left[\mathrm{g} / \mathrm{cm}^{3}\right]$ & 1.7829 & 1.8336 \\
Appearance & White powder & White powder \\
Weight content of surfactant in the Mt [\%] & 20.1 & 22.9 \\
Volume content of surfactant in the Mt [\%] & 51.4 & 51.3 \\
\hline
\end{tabular}


Table 3 The pyrolysized products of organo-montmorillonite Mt 1 at $230{ }^{\circ} \mathrm{C}$

\begin{tabular}{ccclcc}
\hline Label & $\begin{array}{c}\text { Retention } \\
\text { time [min] }\end{array}$ & VOCs & $\begin{array}{l}\text { Chemical } \\
\text { formula }\end{array}$ & Peak area & $\begin{array}{c}\text { Match quality } \\
{[\%]}\end{array}$ \\
\hline Mt1-1 & 11.303 & Tetradecane & $\mathrm{C}_{14} \mathrm{H}_{30}$ & 57283.47 & 98 \\
Mt1-2 & 13.226 & Pentadecane & $\mathrm{C}_{15} \mathrm{H}_{32}$ & 393941.90 & 97 \\
Mt1-3 & 15.115 & Hexadecane & $\mathrm{C}_{16} \mathrm{H}_{34}$ & 316993.15 & 98 \\
Mt1-4 & 16.937 & Heptadecane & $\mathrm{C}_{17} \mathrm{H}_{36}$ & 1026790.00 & 98 \\
Mt1-5 & 18.915 & Octadecane & $\mathrm{C}_{18} \mathrm{H}_{38}$ & 239120.53 & 98 \\
Mt1-6 & 20.569 & Dimethyl palmitamine & $\mathrm{C}_{18} \mathrm{H}_{39} \mathrm{~N}$ & 270687.77 & 90 \\
Mt1-7 & 23.775 & Stearyltrimethylammonium & $\mathrm{C}_{21} \mathrm{H}_{46} \mathrm{ClN}$ & 197096.31 & 59 \\
\hline
\end{tabular}


Table 4 Pyrolysized products of organo-montmorillonite $\mathrm{Mt} 2$ at $230{ }^{\circ} \mathrm{C}$

\begin{tabular}{|c|c|c|c|c|c|}
\hline Code & $\begin{array}{l}\text { Retention } \\
\text { time [min] }\end{array}$ & VOCs & $\begin{array}{l}\text { Chemical } \\
\text { formula }\end{array}$ & Peak area & $\begin{array}{c}\text { Match } \\
\text { quality } \\
{[\%]}\end{array}$ \\
\hline Mt2-1 & 4.880 & Benzaldehyde & $\mathrm{C}_{6} \mathrm{H}_{5} \mathrm{CHO}$ & 280407.30 & 97 \\
\hline Mt2-2 & 5.470 & Benzyl chloride & $\mathrm{C}_{7} \mathrm{H}_{7} \mathrm{Cl}$ & 6807570.00 & 87 \\
\hline $\mathrm{Mt} 2-3$ & 5.673 & $\begin{array}{l}\text { Benzenemethanamine, } \\
\text { N,N-dimethyl- }\end{array}$ & $\mathrm{C}_{9} \mathrm{H}_{13} \mathrm{~N}_{2}$ & 2281360.00 & 93 \\
\hline Mt2-4 & 11.712 & Dodecanal & $\mathrm{C}_{12} \mathrm{H}_{24} \mathrm{O}$ & 133470.08 & 98 \\
\hline Mt2-5 & 12.977 & 1-Decene & $\mathrm{C}_{10} \mathrm{H}_{20}$ & 1086400.00 & 95 \\
\hline Mt2-6 & 13.226 & Pentadecane & $\mathrm{C}_{15} \mathrm{H}_{32}$ & 509450.01 & 97 \\
\hline Mt2-7 & 15.255 & $\begin{array}{c}\text { Dodecanoic acid, ethyl } \\
\text { ester }\end{array}$ & - & 1340980.00 & 97 \\
\hline Mt2-8 & 16.937 & Heptadecane & $\mathrm{C}_{17} \mathrm{H}_{36}$ & 1060160.00 & 98 \\
\hline Mt2-9 & 18.814 & 1-Octadecene & $\mathrm{C}_{16} \mathrm{H}_{32}$ & 528864.89 & 99 \\
\hline Mt2-10 & 18.932 & Octadecane & $\mathrm{C}_{18} \mathrm{H}_{38}$ & 529329.37 & 98 \\
\hline Mt2-11 & 20.316 & 1-Hexadecanethiol & $\mathrm{C}_{16} \mathrm{H}_{34} \mathrm{~S}$ & 260152.38 & 92 \\
\hline Mt2-12 & 20.771 & - & - & 2064140.00 & - \\
\hline Mt2-13 & 23.959 & Dimantine & $\mathrm{C}_{20} \mathrm{H}_{43} \mathrm{~N}$ & 2055960.00 & 87 \\
\hline
\end{tabular}


Table 5 Peak labels in the Py-GC/MS chromatogram of VOCs from base bitumen, Mt1modified and Mt2 modified bitumens, their corresponding compounds and peak areas

\begin{tabular}{|c|c|c|c|c|c|c|c|c|c|}
\hline \multirow[b]{2}{*}{ Labels } & \multirow{2}{*}{$\begin{array}{l}\text { Retention } \\
\text { time [min] }\end{array}$} & \multirow[b]{2}{*}{ Compounds } & \multirow{2}{*}{$\begin{array}{l}\text { Chemical } \\
\text { formula }\end{array}$} & \multicolumn{2}{|c|}{ Base bitumen } & \multicolumn{2}{|c|}{ Mt1 modified bitumen } & \multicolumn{2}{|c|}{ Mt 2 modified bitumen } \\
\hline & & & & Peak area & $\begin{array}{l}\text { Matching } \\
\text { degree[\%] }\end{array}$ & Peak area & $\begin{array}{l}\text { Matching } \\
\text { degree[\%] }\end{array}$ & Peak area & $\begin{array}{l}\text { Matching } \\
\text { degree[\%] }\end{array}$ \\
\hline Base-1 & 6.073 & Nonanal & $\mathrm{C}_{9} \mathrm{H}_{18} \mathrm{O}$ & 49976.78 & 83 & 21224.95 & 55 & 54318.24 & 83 \\
\hline Base-3 & 9.366 & Tridecane & $\mathrm{C}_{13} \mathrm{H}_{28}$ & 60082.68 & 98 & 67118.60 & 93 & 23160.03 & 98 \\
\hline Base-4 & 11.168 & 1-Pentadecene & $\mathrm{C}_{15} \mathrm{H}_{30}$ & 16323.30 & 97 & 0.00 & - & 0.00 & - \\
\hline Base-6 & 12.589 & $\begin{array}{c}\text { 2-[2-(2-butoxyetho } \\
\text { xy) ethoxy]- }\end{array}$ & $\mathrm{C}_{10} \mathrm{H}_{22} \mathrm{O}_{4}$ & 39123.01 & 85 & 24927.48 & 75 & 33518.86 & 79 \\
\hline Base-7 & 13.226 & Pentadecane & $\mathrm{C}_{15} \mathrm{H}_{30}$ & 72390.86 & 97 & 57513.06 & 98 & 60184.32 & 97 \\
\hline Base-8 & 14.988 & Cetene & $\mathrm{C}_{16} \mathrm{H}_{32}$ & 35462.65 & 99 & 0.00 & - & 0.00 & - \\
\hline Base-9 & 15.115 & Hexadecane & $\mathrm{C}_{16} \mathrm{H}_{34}$ & 85331.54 & 97 & 51101.84 & 97 & 46614.79 & 97 \\
\hline Base-13 & 20.147 & Diethylpropion & $\mathrm{C}_{13} \mathrm{H}_{19} \mathrm{NO}$ & 11104.81 & 64 & 16996.49 & 91 & 9465.80 & 64 \\
\hline Base-14 & 20.378 & Nonadecane & $\mathrm{C}_{19} \mathrm{H}_{40}$ & 24314.29 & 98 & 0.00 & - & 18114.11 & 98 \\
\hline Base-15 & 22.004 & Eicosane & $\mathrm{C}_{20} \mathrm{H}_{42}$ & 12442.37 & 99 & 8973.96 & 99 & 2736.66 & 99 \\
\hline Base-16 & 23.554 & Heneicosane & $\mathrm{C}_{21} \mathrm{H}_{44}$ & 8718.61 & 98 & 0.00 & - & 0.00 & - \\
\hline Base-17 & 24.600 & Diisooctyl maleate & $\mathrm{C}_{20} \mathrm{H}_{36} \mathrm{O}_{4}$ & 5331.12 & 83 & 30260.76 & 91 & 0.00 & 92 \\
\hline Base-18 & 25.726 & - & - & 85556.41 & - & 0.00 & - & 140090.52 & - \\
\hline
\end{tabular}




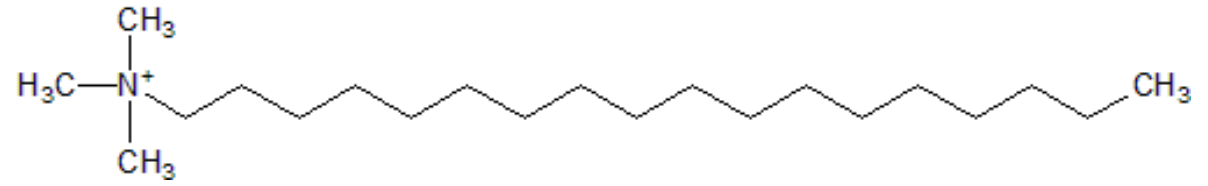

(a) Octadecyl trimethyl ammonium cation

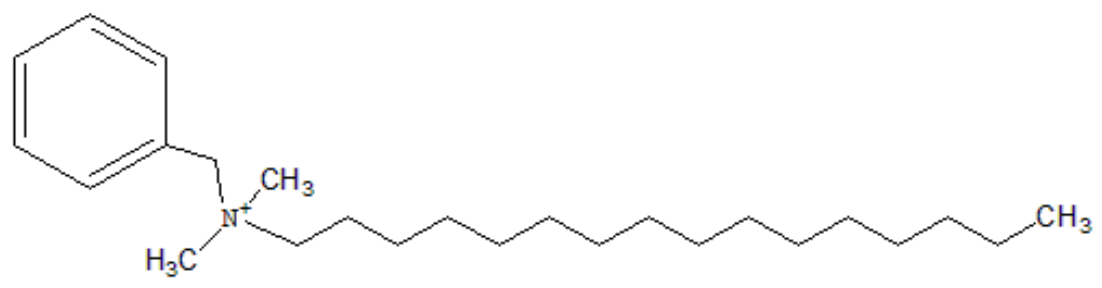

(b) Benzyl dimethyl hexadecyl ammonium cation

Figure 1 Schematic molecular structures of quaternary ammonium salt cations: (a) in Mt1 and (b) in Mt2 


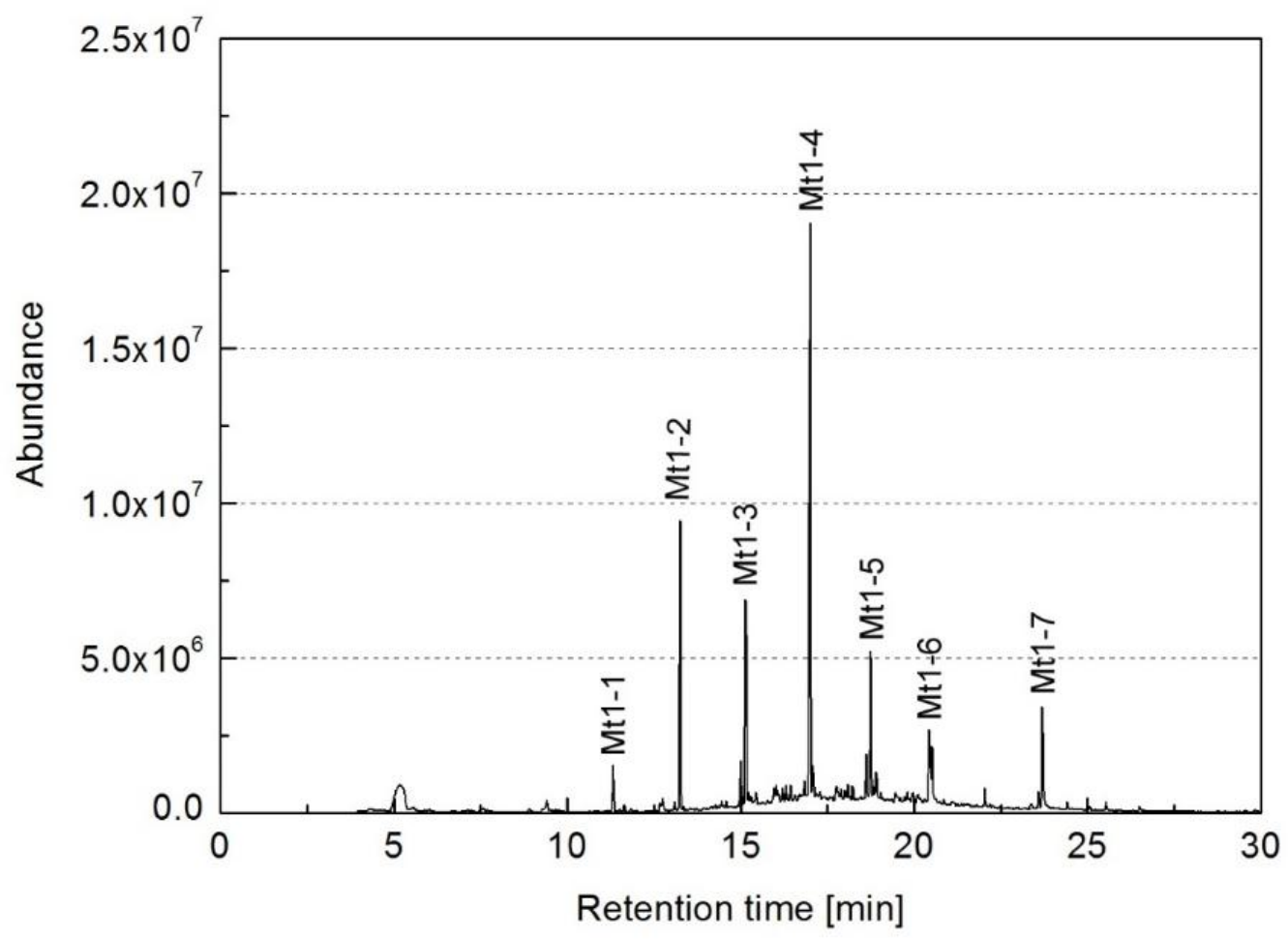

(a)

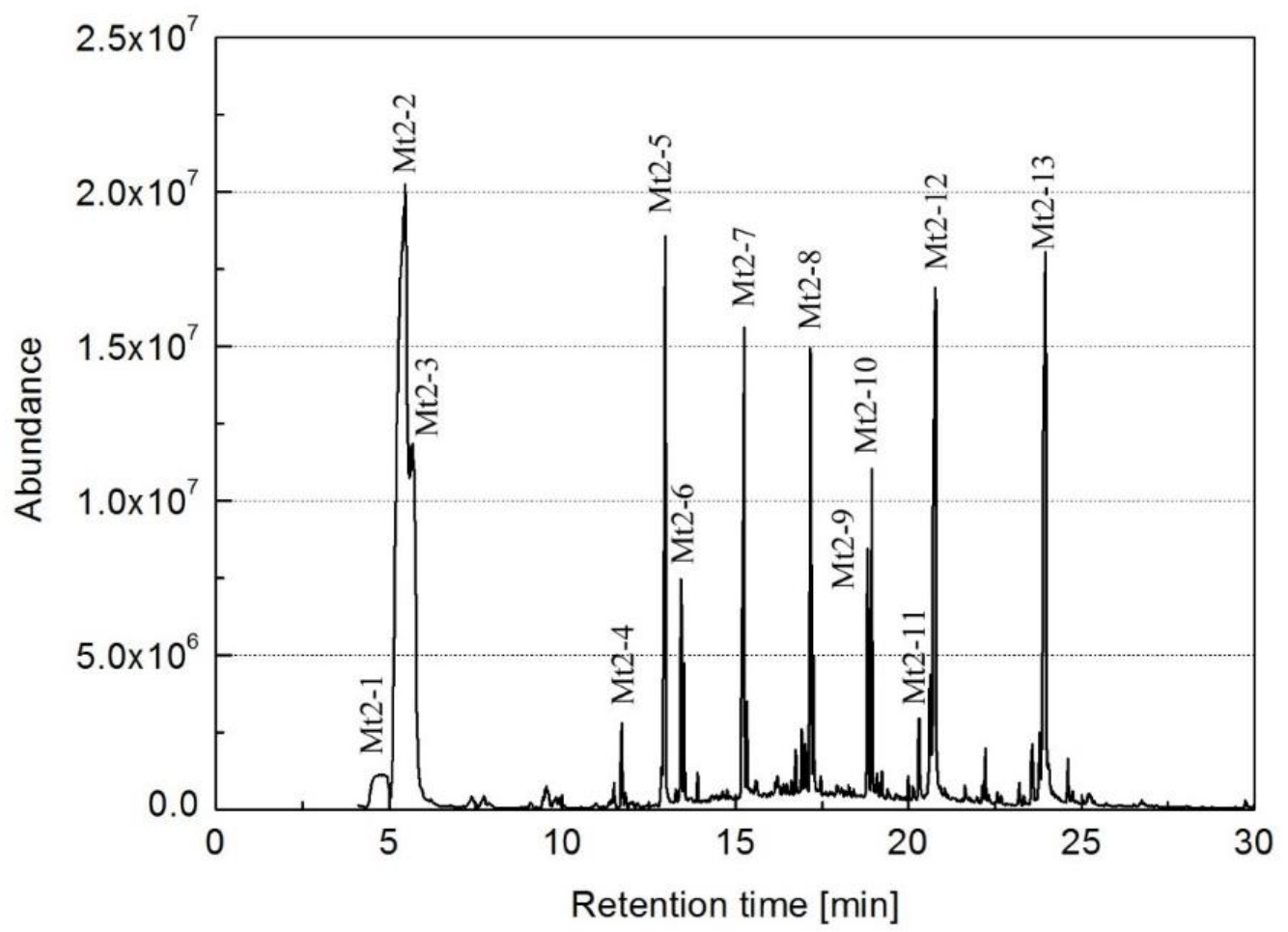

(b)

Figure 2 Py-GC/MS chromatogram of organo-montmorillonites for (a) Mt1 and (b) Mt2 

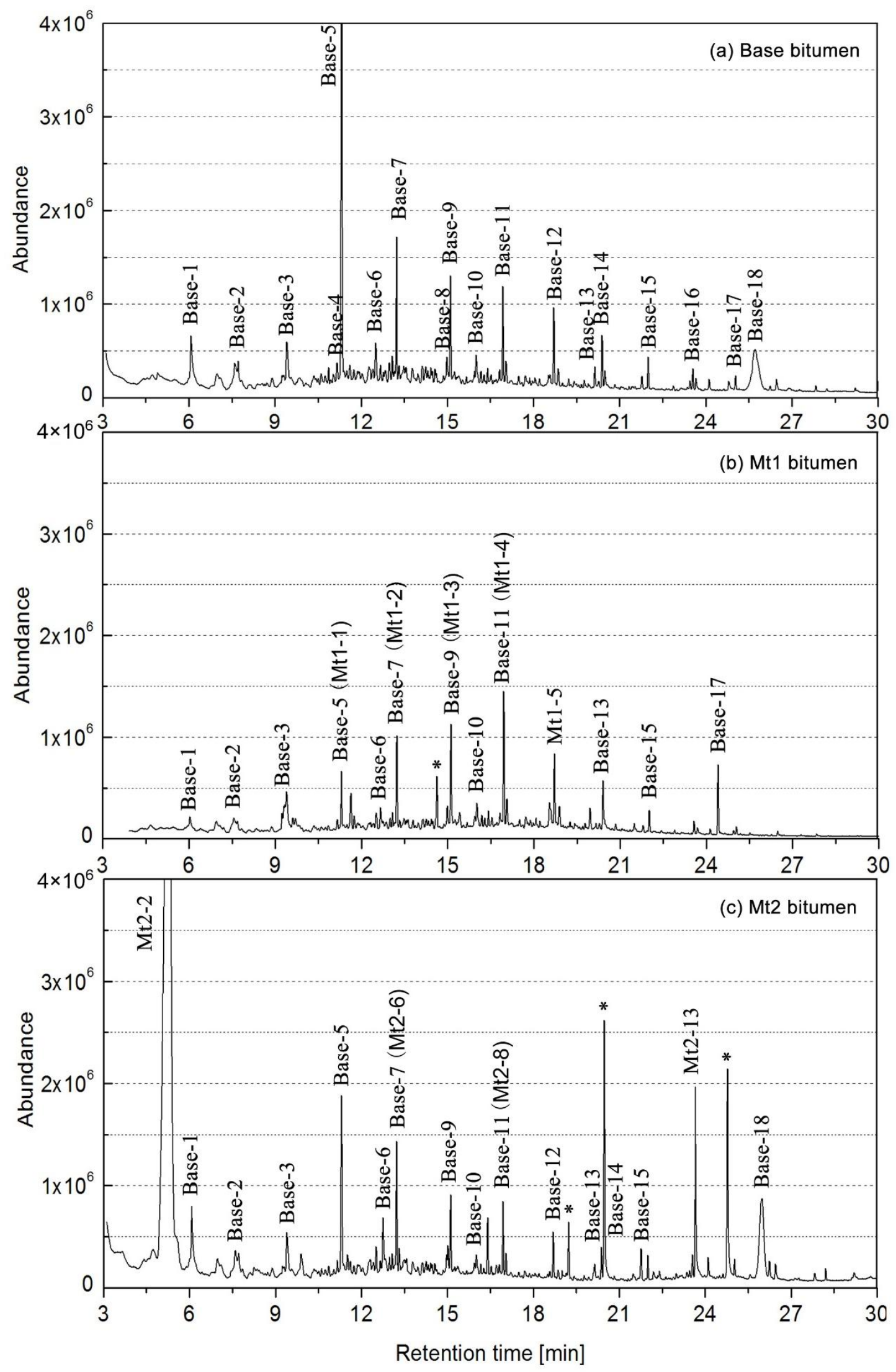

Figure 3 The Py-GC/MS chromatograms of (a ) base bitumen (b) Mt1 modified bitumen (c) Mt2 modified bitumen (“*” in the figure means new compounds synthesized due to the thermal cracking of modified bitumen ) 


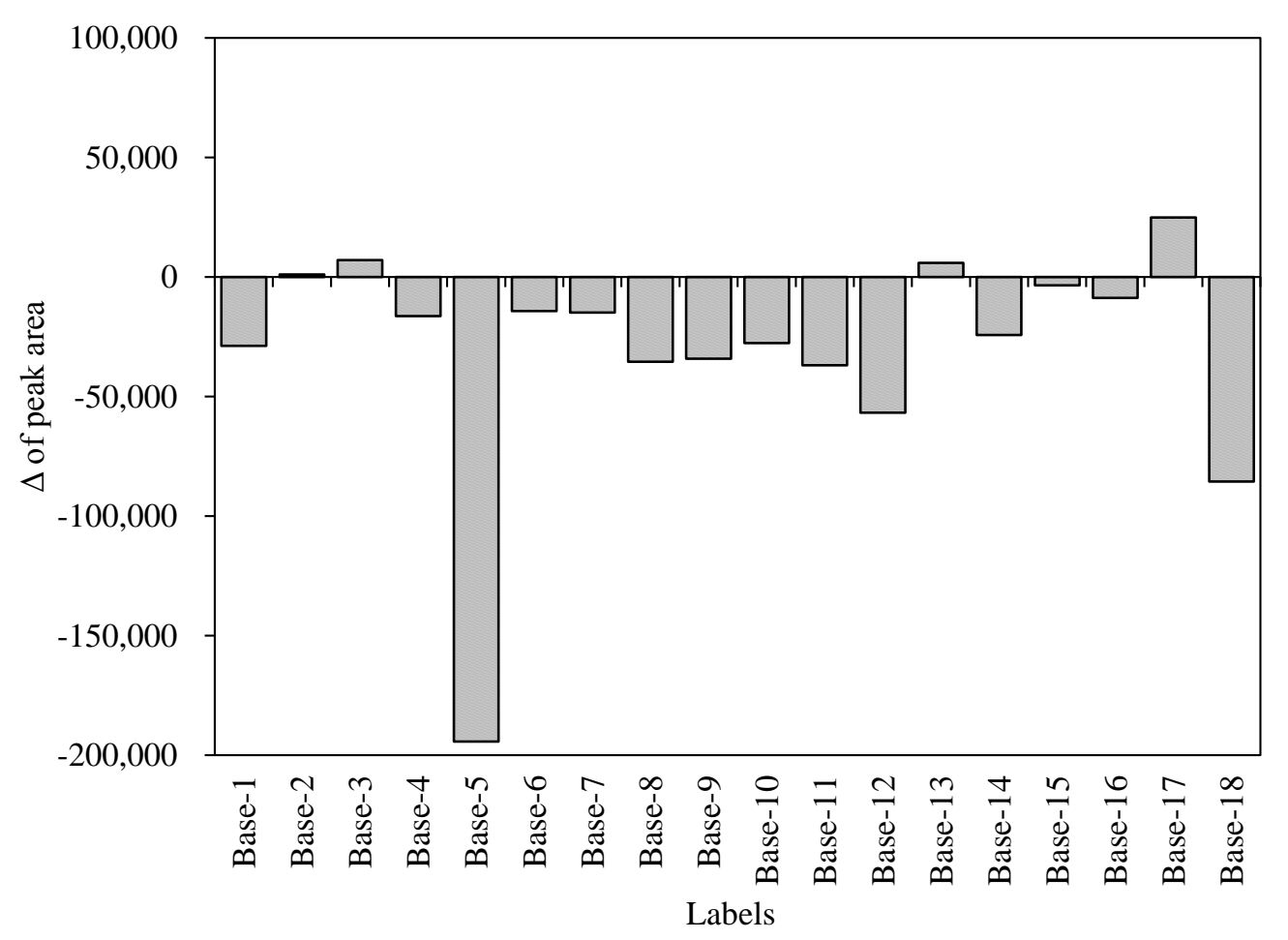

(a)

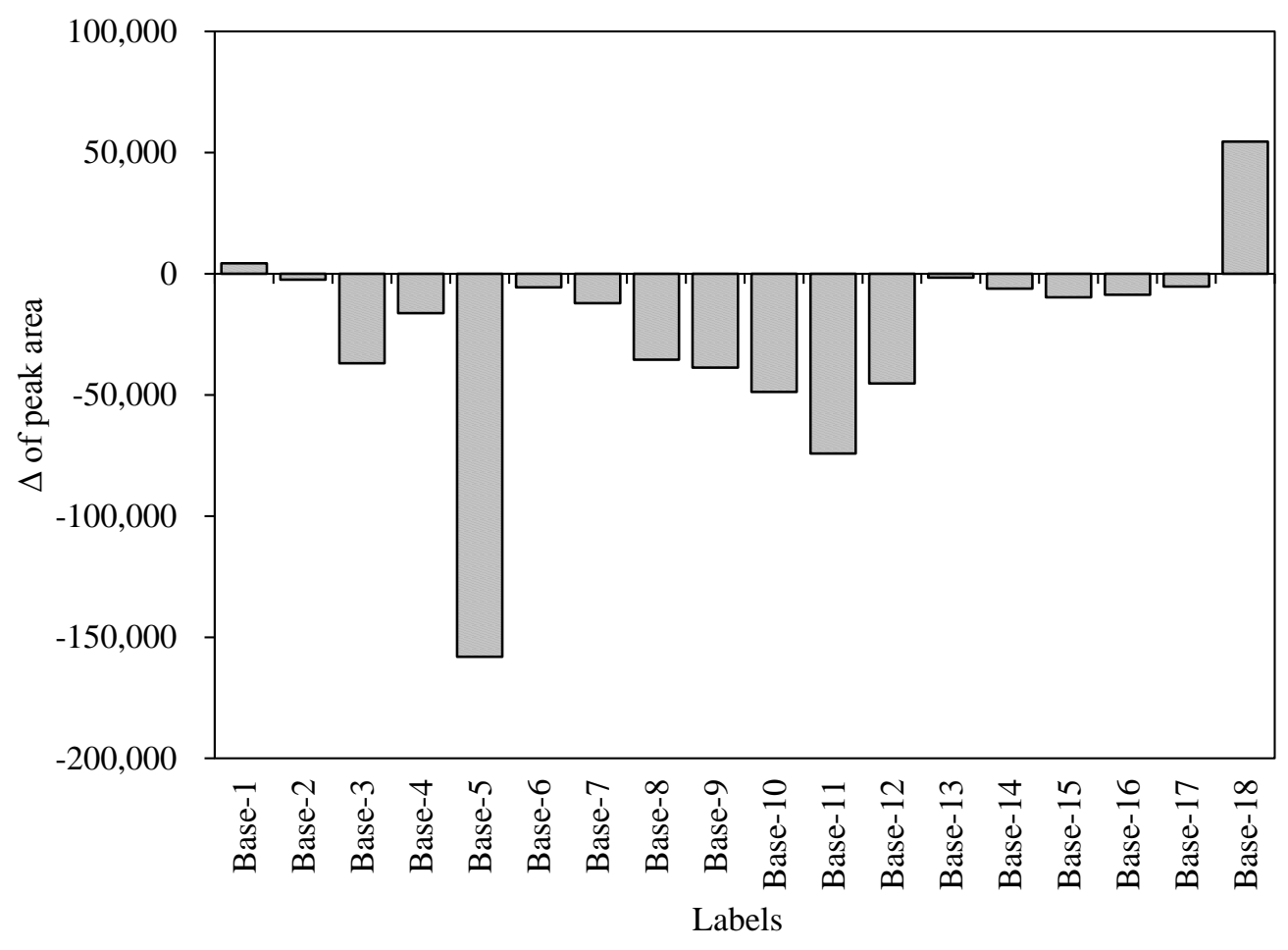

(b)

Figure 4 Change in the peak area of VOCs in the base bitumen after modification with (a) Mt1 and (b) Mt2 


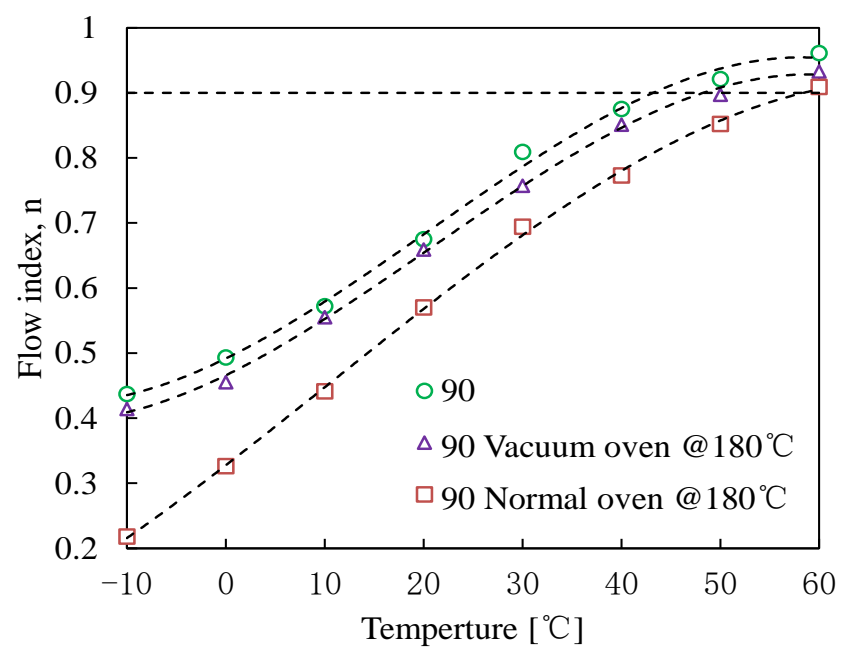

(a)

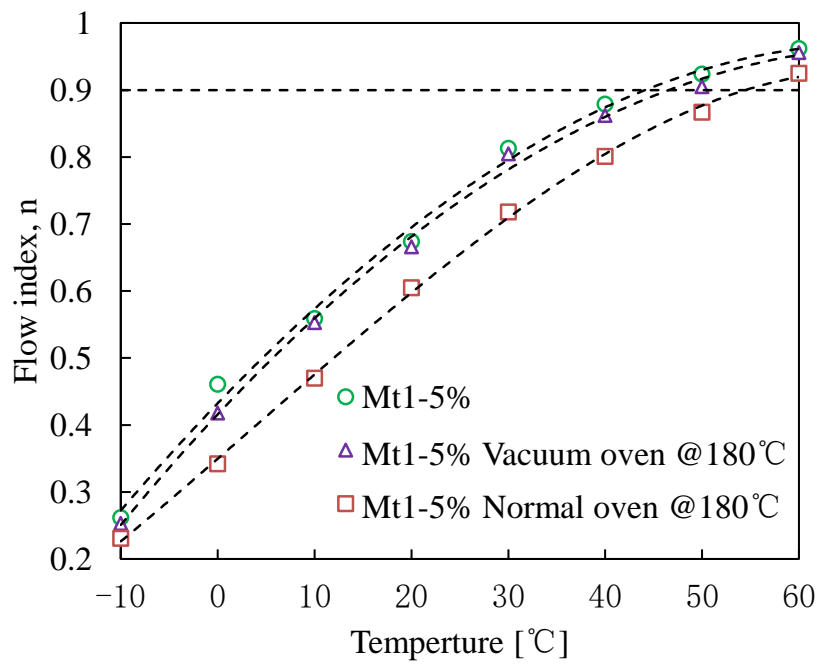

(b)

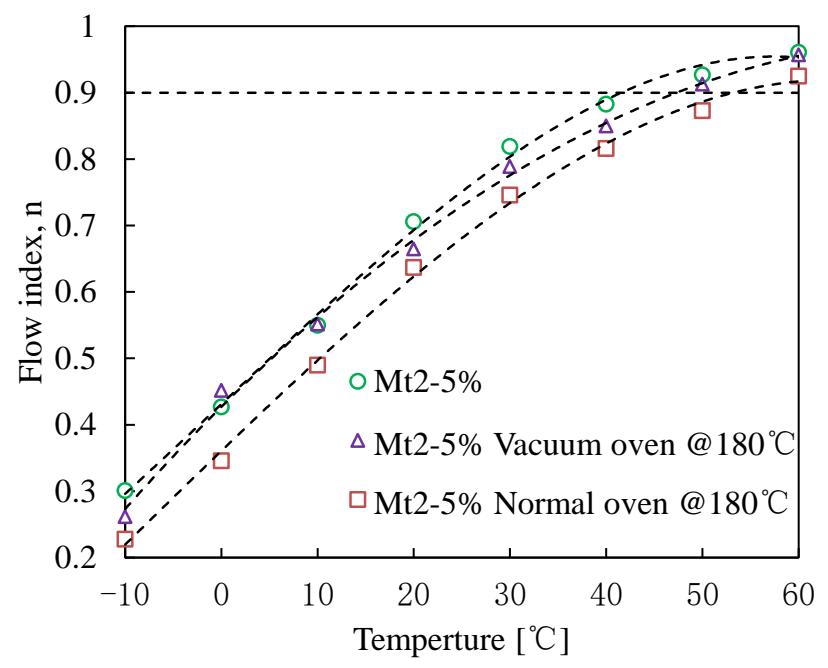

(c)

Figure 5 Flowability before and after different oven ageing for (a) base bitume, (b) Mt1 modified bitumen and (c) Mt2 modified bitumen 